\title{
Direct Electron Transfer of Glucose Oxidase in Carbon Paper for Biofuel Cells and Biosensors
}

\author{
Zongqian $\mathrm{Hu}^{1}$, Zepeng Kang ${ }^{2}$, Chao $\mathrm{Yu}^{1}$, Bing Wang ${ }^{3}$, Shuqiang Jiao ${ }^{2, *}$, Ruiyun Peng ${ }^{1, *}$ \\ ${ }^{1}$ Beijing Institute of Radiation Medicine, Beijing, 100850, P.R. China. \\ ${ }^{2}$ State Key Laboratory of Advanced Metallurgy, University of Science and Technology Beijing, \\ Beijing, 100083, P.R. China. \\ ${ }^{3}$ Beijing Institute of System Engineering, Beijing, 100101, P.R. China. \\ *E-mail: pengry@bmi.ac.cn, sjiao@ustb.edu.cn
}

doi: $10.20964 / 2017.08 .24$

Received: 17 February 2017 / Accepted: 27 May 2017 / Published: 12 July 2017

Advanced bioelectronic devices, such as high-power biofuel cells (BFCs) and highly efficient biosensors, are limited by the difficulty of electron transfer between enzymes and electrodes. Previously reported methods for achieving electron transfer from enzymes to electrodes have relied on the use of complex biomolecule immobilization procedures, complicated matrix materials, or enzyme engineering, resulting in potential relative toxicity, high cost, as well as limited stability. Here, we report a facile method for the rapid preparation of a glucose oxidase (GOx) anode with direct electron transfer (DET) for glucose BFCs and biosensors. GOx is directly incorporated into pretreated carbon paper $(\mathrm{CP})$ by adjusting the $\mathrm{pH}$ of the incubation medium during the immobilization process. Eexcellent bioelectrocatalytic activity is obtained when GOx is incorporated into CP near the pI of GOx. The electron transfer rate constant $\left(k_{s}\right)$ and the apparent Michaelis-Menten constant $\left(K_{M}^{a p p}\right)$ are

estimated to be $12.08 \pm 1.0 \mathrm{~s}^{-1}$ and $0.13 \pm 0.01 \mathrm{mM}$, respectively. These findings may be extended to the development of highly conductive nanomaterials and the immobilization of other enzymes or biomolecules, providing a promising platform for the development of BFCs, biosensors, and other bioelectrochemical devices.

Keywords: direct electron transfer; electrostatic adsorption; glucose oxidase; biofuel cells

\section{FULL TEXT}

(C) 2017 The Authors. Published by ESG (www.electrochemsci.org). This article is an open access article distributed under the terms and conditions of the Creative Commons Attribution license (http://creativecommons.org/licenses/by/4.0/). 